\title{
Local experimental studies of the fertilizer uptake process into suction pipelines of pumping stations with a jet apparatus
}

\author{
Sergey Tarasyants*, Vladislav Panov, Yulia Urzhumova, and Vladimir Rudakov \\ Novocherkassk Engineering and Reclamation Institute named after A.K. Kortunov, Don State \\ Agrarian University, 346428, Novocherkassk, Russia
}

\begin{abstract}
Determination of the total energy in the suction pipeline of a four-component mixer of fertilizers and water in an experimental way, for the possibility of its use in various schemes of cropsirrigation has been performed. Materials and methods: The research was carried out at an operating pumping station LLC "Rassvet" Kuibyshevsky district of Rostov region on a specially made installation using calibrated control and measuring devices in accordance with GOST 24028-80 "Research tests". The experimental results' processing was carried out according to the recommendations of V.N. Voznesensky on the theory of experiment planning. The experiments were carried out in two stages, the first to determine the factors influencedegree: $\mathrm{B}_{1}-$ mixer vacuum value, accepted values $0 \div 9 \mathrm{~m}, \mathrm{~B}_{2}$ - vacuum value in the suction pipe of a centrifugal pump, assumed values $0 \div 5 \mathrm{~m}, \mathrm{H}_{1}$ - the head of the jet pump, taken within $0 \div 25$ $\mathrm{m}$, at full energy in the suction pipe of the mixerS (pressure + velocity head), which subsequently determined all the hydraulic parameters of the mixer suction line (pipe diameters, distance of mixture transportation, head loss in the suction pipeline. According to the first stageresults, the influencedegree of the factors on the criterion was determined - the mixer head is $66.37 \%$, the mixer head mixer pipeline $26.32 \%$, mixer vacuum $7.3 \%$ The second stage was carried out with the two most significant factors, the mixer head $\mathrm{H}^{\mathrm{I}}$ and vacuum in the suction pipe of the pump $\mathrm{B}_{2}$. Based on the results of the second group of experiments, an equation, the analysis of which made it possible to determine the value of the variationstudied intervals criterion was obtained.
\end{abstract}

\section{Introduction}

Literary sources provide a number of methods for mixing and introducing organic and mineral fertilizers into the irrigation network:

- Mixing method in a mixing tank [1] (Figure 1);

- Method of feeding and mixing fertilizers using an injector [2] (Figure 2);

\footnotetext{
* Corresponding author: goodga@mail.ru
} 


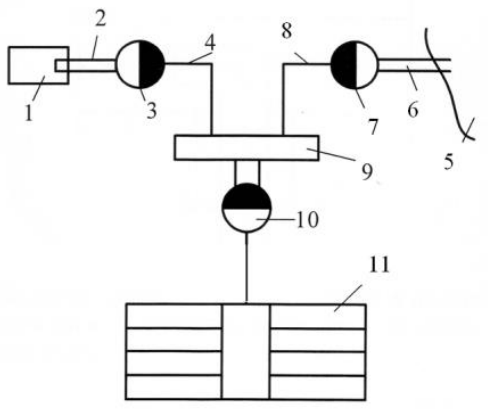

Fig. 1. Scheme of mixing fertilizers with water in a mixing tank: 1 - pressure pipeline; 2 injector; 3 - coupler for injector input; 4 flange; 5 - fertilizer supply pipeline

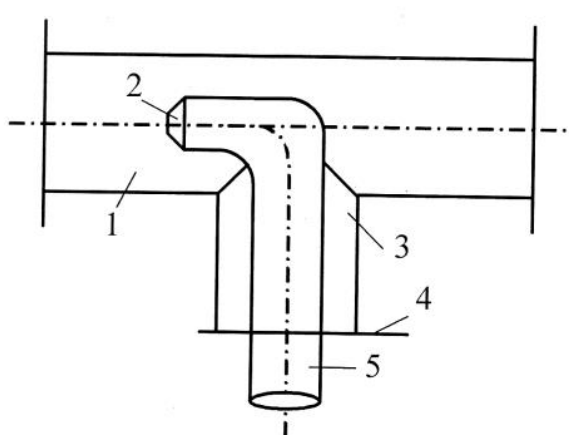

Fig. 2. Injector for uptake fertilizers into the discharge pipeline of the irrigated area

Method of fertilizing using mobile transport (Table 1).

Table 1. Characteristics of mobile and trailed spreaders

\begin{tabular}{|c|c|c|c|c|c|c|}
\hline \multirow[b]{2}{*}{ Indicator } & \multicolumn{3}{|c|}{ Tractor tanks } & \multicolumn{3}{|c|}{ Tank trucks } \\
\hline & RJT-4 & RJT-8 & $\begin{array}{c}\text { RJT- } \\
16\end{array}$ & $\begin{array}{c}\text { RJU- } \\
3,6\end{array}$ & RJU-8 & $\begin{array}{c}\text { For } \\
\text { KAMAZ }\end{array}$ \\
\hline Capacity, $\mathrm{m}^{3}$ & 5 & 8 & 16 & 3,6 & 8 & 16 \\
\hline Aggregated & $\begin{array}{l}\text { MTZ- } \\
80\end{array}$ & $\begin{array}{c}\mathrm{T}-150 \\
\mathrm{~K}\end{array}$ & $\begin{array}{l}\mathrm{K}- \\
701\end{array}$ & $\begin{array}{c}\text { GAZ- } \\
53 \mathrm{~A}\end{array}$ & $\begin{array}{l}\text { ZIL- } \\
130 \mathrm{~B}\end{array}$ & KAMAZ \\
\hline Mantained & \multicolumn{3}{|c|}{ By tractor driver } & \multicolumn{3}{|c|}{ By driver } \\
\hline $\begin{array}{l}\text { Cisterns } \\
\text { filling }\end{array}$ & \multicolumn{3}{|c|}{ Self-loading, loader } & \multicolumn{3}{|c|}{ Self-loading } \\
\hline $\begin{array}{c}\text { Filling time, } \\
\text { min. }\end{array}$ & $3-4$ & $5-6$ & 5 & $3-4$ & $4-5$ & $6-8$ \\
\hline $\begin{array}{l}\text { Machine } \\
\text { weight, } \mathrm{t}\end{array}$ & 2.4 & 3.8 & 6.2 & 1.34 & 3.8 & 6.2 \\
\hline $\begin{array}{l}\text { Application } \\
\text { rate, } t / h a\end{array}$ & $6-50$ & $7-60$ & $10-30$ & $6-50$ & $7-60$ & $10-80$ \\
\hline $\begin{array}{c}\text { Capture } \\
\text { width, m }\end{array}$ & $7-11$ & $10-12$ & $10-15$ & $7-11$ & $10-12$ & $10-15$ \\
\hline $\begin{array}{l}\text { Productivity } \\
\text { with radius of } \\
\text { transport } \\
\text { operation } \\
3 \mathrm{~km}, \mathrm{t} / \mathrm{h}\end{array}$ & 6 & 11.5 & 18 & 5.5 & 13 & 25 \\
\hline
\end{tabular}

Each of the above-mentioned methods has its own advantages and disadvantages.

In this paper, two methods of fertilization using an annular four-component two-surface jet mixer (Figure 3) are considered as the most progressive and economical mixer that has been pre-tested during irrigation process [3]. 


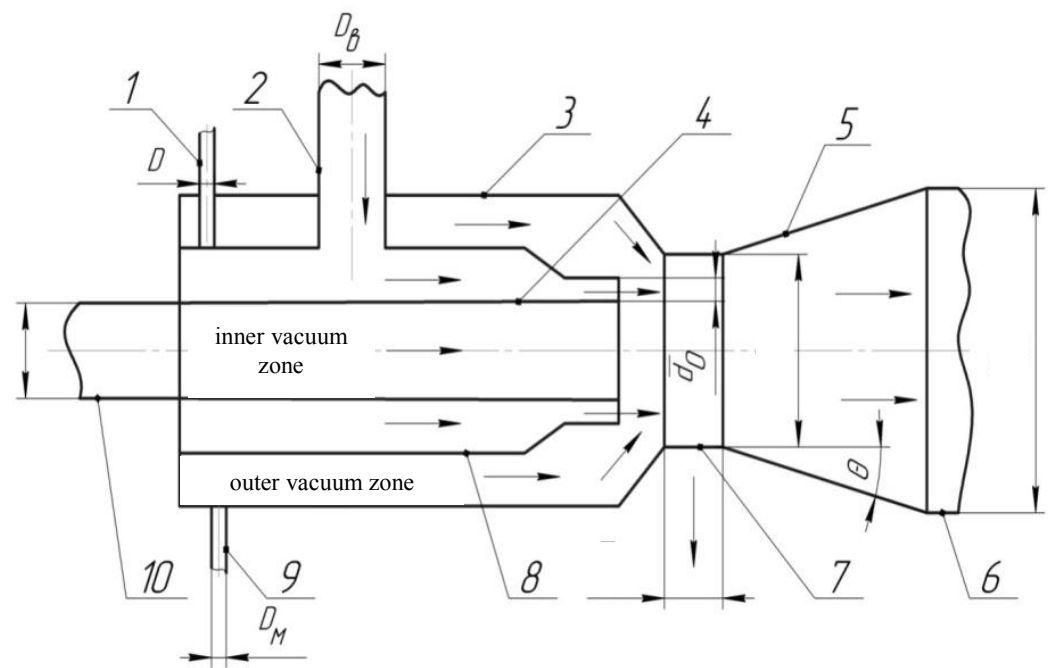

Fig. 3. Structural diagram of a jet four-component fertilizer mixer: 1 - mineral fertilizers supply pipeline; 2 - operatingwatersupply pipeline; 3 - external body of the mixer; 4 - inner nozzle of the annular nozzle; 5 - diffuser; 6 - pipeline for withdrawing a mixture of fertilizers and water; 7 - mixing chamber; 8 - outer nozzles of the annular nozzle; 9 - microelements supply pipeline; 10 - pipeline for supplying livestock waste

1. Method of applying mineral fertilizers during fertilizing irrigation of corn for grain in LLC "Rassvet” Kuibyshevsky district of the Rostov region (Figure 4, 5).
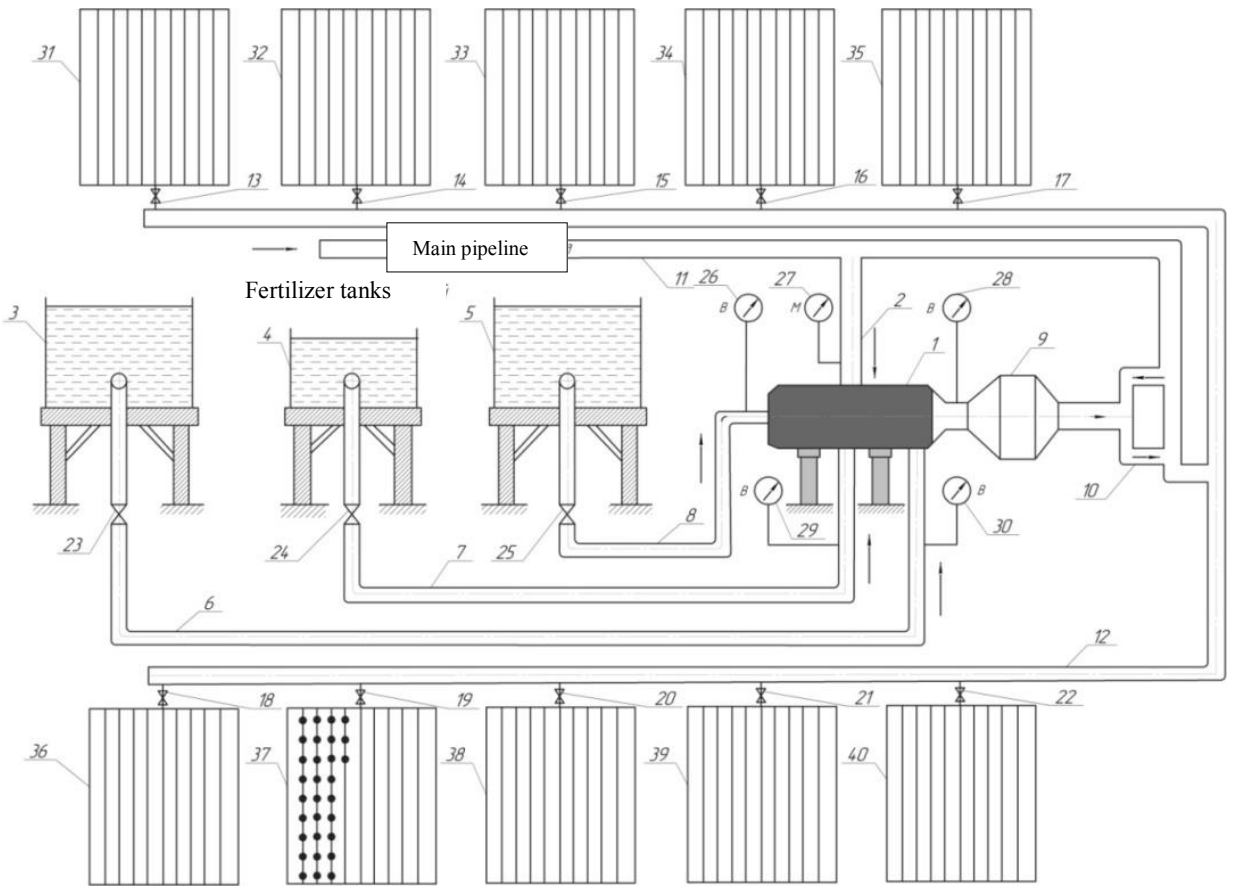

Fig. 4. Scheme of applying mineral fertilizers: 1- jet apparatus; 2 - operating pipeline; 3, 4, 5 containers for fertilizers; $6,7,8$ - suction pipelines; 9- pressure pipeline; 10 - bypass; 11 - main pipeline; 12 - distribution pipeline; 13, 14, 15, 16, 17, 18, 19, 20, 21, 22, 23, 24, 25 - valves; 26, 27, $28,29,30$ - manometers; $31,32,33,34,35,36,37,38,39,40$ - irrigation areas 


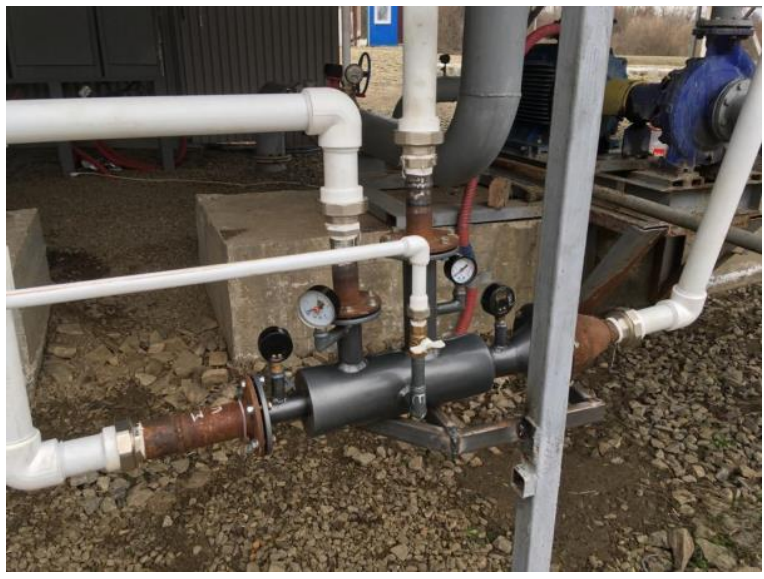

Fig. 5. Introduction of mineral fertilizers into the suction pipeline of the pumping station using a fourcomponent jet mixer (photo by S. Tarasyants)

2. Method of applying livestock runoff and mineral fertilizers during fertilizing irrigation of perennial grasses at a pig-breeding complex LLC "Kalalinskoye" Stavropol Krai with the mixture intake into the suction pipeline of the pumping station (Figure 6,7).

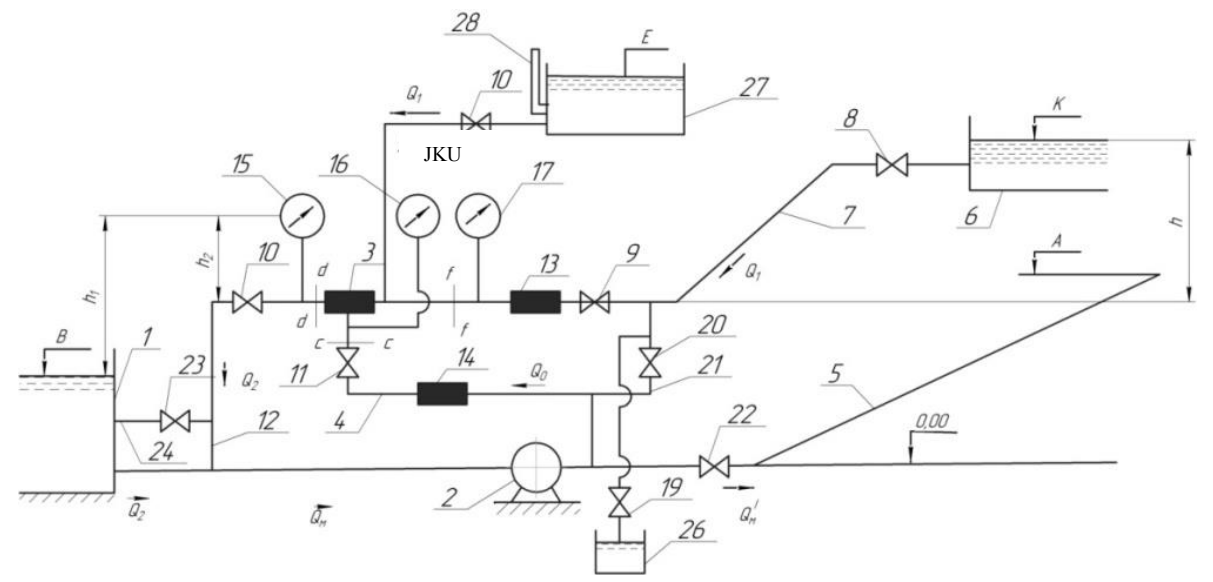

Fig. 6. Technological diagram of the system for mixing with jet mixerthe livestock wastewater and water LLC "Kalalinskoye" Stavropol Krai: 1- pure water storage; 2 - pumping unit; 3 - mixer; 4 pipeline for supplying working flow to the mixer; 5 - pipeline for supplying a mixture of manure with water to the irrigated area; 6 - storage tank for liquid manure; 7 - liquid manure supply pipeline; 8,9 , $10,11,20,22,23$ - valves; 12 - pipeline for supplying liquid manure to the suction branch pipe of the centrifugal pump; 13, 14 - flow meters; 15, 16 - manometers; 17 - manovacuum meter; 18 - border of the pumping station building; 19 - drain cock; 21 - flushing pipeline; 24 - pipeline for supplying effluents to the storage device; 26 - drainage pit; 27 - container for complex fertilizers liquid; 28 piezometer 


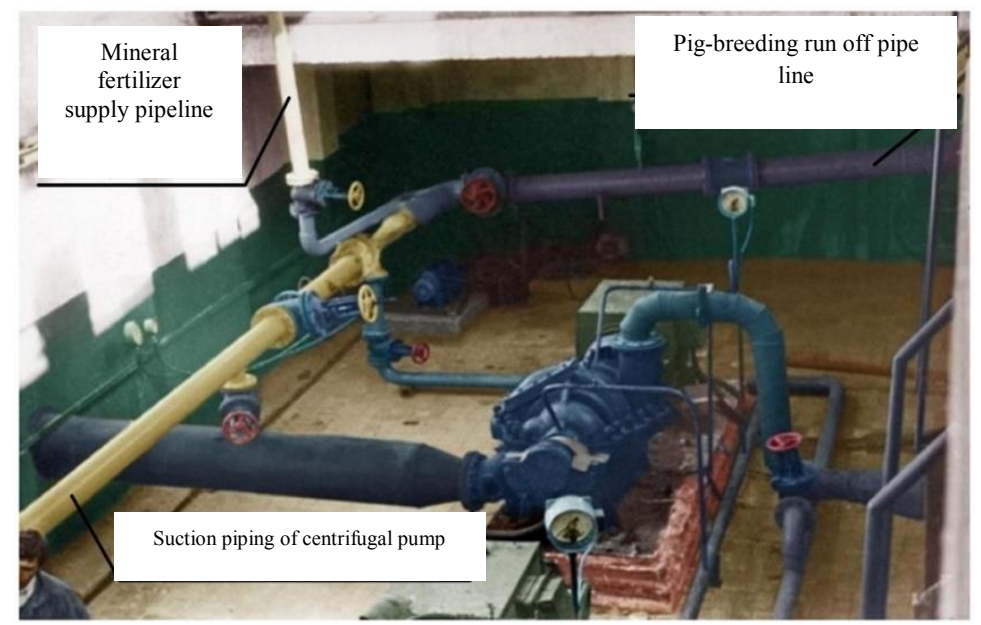

Fig. 7. Injection of livestock wastewater and mineral fertilizers into the suction pipeline of the pumping station LLC "Kalalinskoye" Stavropol Territory (general view of the pumping station).

Both methods shown in the diagrams were used at pumping stations with a positive suction height and with forced introduction of fertilizers using a jet mixer capable of creating a vacuum in the suction zone up to $9 \mathrm{~m}$ and a pressure in the delivery zone up to 20 m.In addition, when using a jet mixer, it is possible to regulate the fertilizer supply.

\section{Materials and methods}

To identify possible values of the mixer feeds, the experiments at a pumping station LLC "Rassvet" using the theory of experiment planning were carried out [4] according to the scheme (Figure 8) for determining the potential energy (referred to the unit of weight and expressed in meters of pumped liquid - water) as factors were used:

$B_{1}\left(x_{1}\right)$ is the amount of vacuum in the mixer housing, the accepted values $0 \div 9 \mathrm{~m}$.

$B_{2}\left(x_{2}\right)$ is the value of vacuum in the suction pipe of the centrifugal pump, taken within $0 \div 5 m$ (pump D 320-70) (Figure 9).

$H_{1}\left(x_{3}\right)$ is the head of the jet pump, taken within $0 \div 20 \mathrm{~m}$.

The potential energy per unit weight of the pumped liquid in meters in the suction line of the jet mixer was determined as a criterion (see Figure 8 ) $S=\frac{P_{5}}{g \rho_{0}}$, by which all the hydraulic parameters of the suction line of the jet mixer were subsequently determined. A centrifugal pump was used to supply working water to the mixer D 320-70. The pressureflow characteristic is shown in Figure 9. 


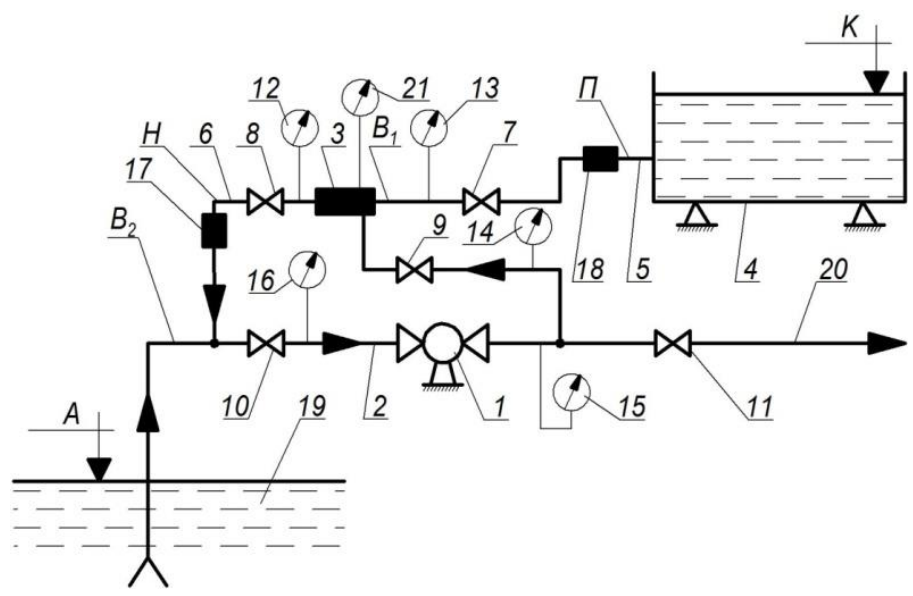

Fig. 8. Scheme of equipment and instruments installation during research: 1-centrifugal pump; 2suction pipe of the centrifugal pump; 3-jet mixer; 4-container for fertilizers; 5-suction line of the jet mixer; 6-pressure pipe of the jet mixer; 7,8,9,10,11-valves; 12,13,21 -combined pressure gage; 14,15,16-pressure gauges; 13 - vacuum gauge; 17.18 flow meters; 19-water source; 20-pressure pipe of the centrifugal pump

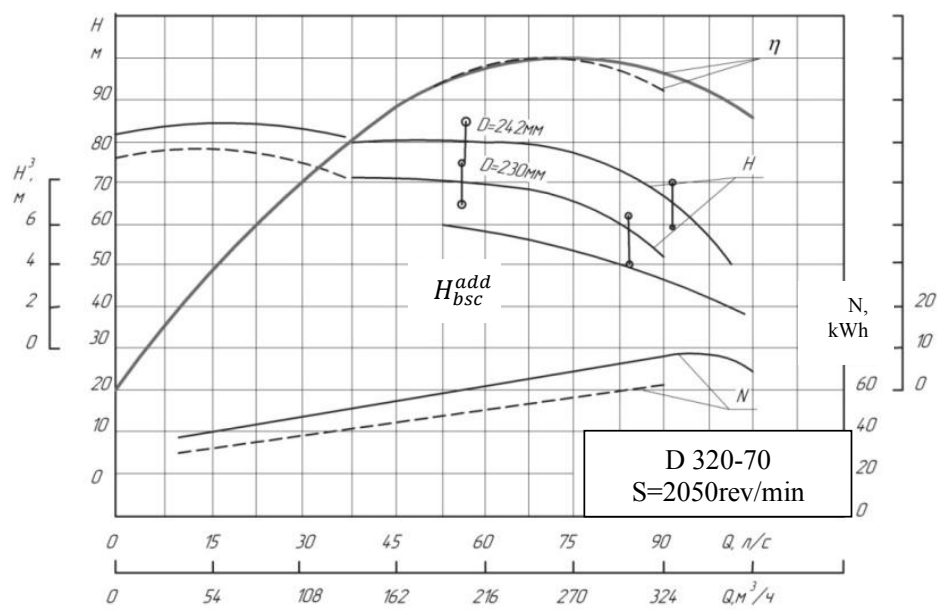

Fig. 9. Pump head-flow characteristic D 320-70, used for the research.

In field studies, two groups of experiments were carried out.

The first is to determine the influence degree of each factor $B_{1}\left(x_{1}\right) ; B_{2}\left(x_{2}\right) ; H\left(x_{3}\right)$ by the amount of energy $S$ in the suction pipe of the mixer. For research at the first stage, a threefactor plan was adopted. Factors and intervals of variation are shown in Table 1 and assigned based on a previous literature review $[5,6,7,8,9]$.

Table 1. Actual and coded values of factors for the first group of experiments

\begin{tabular}{|c|c|c|c|c|c|}
\hline \multirow{2}{*}{ Factors } & \multirow{2}{*}{ Code } & Intervals, & \multicolumn{3}{|c|}{ Level } \\
\cline { 4 - 6 } & & $\mathrm{m}$ & Average, "0", $\mathrm{m}$ & Lower, $\mathrm{m}$ & Upper, $\mathrm{m}$ \\
\hline$B_{1}$ & $x_{1}$ & 2.0 & $6.0(0)$ & $4.0(-)$ & $8.0(+)$ \\
\hline$B_{2}$ & $x_{2}$ & 1.0 & $3.0(0)$ & $2.0(-)$ & $4.0(+)$ \\
\hline$H$ & $x_{3}$ & 6.0 & $10.0(0)$ & $6.0(-)$ & $14.0(+)$ \\
\hline
\end{tabular}


Matrix and research results are shown in Table 2.

Table 2. The planning matrix and the results of the first group of experiments

\begin{tabular}{|c|c|c|c|c|c|c|c|}
\hline \multirow{2}{*}{$\begin{array}{c}\text { Experi } \\
\text {-ment } \\
\text { no. }\end{array}$} & \multirow{2}{*}{$\begin{array}{c}\text { Mixer } \\
\text { body } \\
\text { vacuum } \\
B_{1}\left(x_{1}\right)\end{array}$} & \multirow{2}{*}{$\begin{array}{c}\text { Vacuum in } \\
\text { the suction } \\
\text { pipe of the } \\
\text { pump } \\
B_{2}\left(x_{2}\right)\end{array}$} & \multirow{2}{*}{$\begin{array}{c}\text { Mixer } \\
\text { head } \\
H\left(x_{3}\right)\end{array}$} & \multicolumn{3}{|c|}{ Factor values, $\mathrm{m}$} & \multirow{2}{*}{$\begin{array}{c}\text { Criterion } S, \\
\mathrm{~m}\end{array}$} \\
\hline & & & & $B_{1}\left(x_{1}\right)$ & $B_{2}\left(x_{2}\right)$ & $H\left(x_{3}\right)$ & \\
\hline 1 & + & + & 0 & -8.0 & -5.0 & 12.0 & 12.4 \\
\hline 2 & + & - & 0 & -8.0 & -3.0 & 12.0 & 10.1 \\
\hline 3 & - & + & 0 & -4.0 & -5.0 & 12.0 & 10.8 \\
\hline 4 & - & - & 0 & -4.0 & -3.0 & 12.0 & 5.4 \\
\hline 5 & + & 0 & + & -8.0 & -3.0 & 18.0 & 15.6 \\
\hline 6 & + & 0 & - & -8.0 & -3.0 & 6.0 & 5.4 \\
\hline 7 & - & 0 & + & -4.0 & -3.0 & 18.0 & 14.4 \\
\hline 8 & - & 0 & - & -4.0 & -3.0 & 6.0 & 10.0 \\
\hline 9 & 0 & + & + & -4.0 & -5.0 & 18.0 & 14.6 \\
\hline 10 & 0 & + & - & -4.0 & -5.0 & 6.0 & 11.9 \\
\hline 11 & 0 & - & + & -4.0 & -3.0 & 18.0 & 15.0 \\
\hline 12 & 0 & - & - & -4.0 & -3.0 & 6.0 & 8.2 \\
\hline 13 & 0 & 0 & 0 & -4.0 & -3.0 & 12.0 & 13.0 \\
\hline
\end{tabular}

Processing the results (determining the value of the intercept and coefficients for the

\begin{tabular}{|l|l|l|l|l|l|l|l|}
\hline & $\sum(+)=43.5$ & $\sum(+)=55.0$ & $\sum(+)=59.6$ & & & & OS=14 \\
& $\sum(-)=40.8$ & $\sum(-)=33.3$ & $\sum(-)=35.6$ & & & & 3.6 \\
& $1 B_{1}=-2.7$ & $2 B_{2}=-21.8$ & & & & & \\
\hline & & & & & & & \\
\hline & $x_{1}^{2}\left(B_{1}\right)=84.1$ & $x_{2}^{2}\left(B_{2}\right)=103.0$ & $x_{3}^{2}(H)=158.3$ & & & & \\
& $B_{1}\left(x_{1}\right) \cdot B_{2}\left(x_{2}\right)$ & $B_{1}\left(x_{1}\right) \cdot H\left(x_{3}\right)$ & $B_{2}\left(x_{2}\right) \cdot H\left(x_{3}\right)$ & & & & \\
& $\sum(+)=12.4$ & $\sum(+)=25.6$ & $\sum(+)=22.8$ & & & & \\
& $\sum(-)=16.2$ & $\sum(-)=0$ & $B_{2} H=-4.1$ & & & & \\
& $B_{1} B_{2}=-3.8$ & $B_{1} B_{3}=+25.6$ & & & & & \\
\hline
\end{tabular}

$$
\begin{gathered}
\rho_{1}=-\frac{1}{2} O S=-\frac{1}{2} \cdot 143.6=-71.8 ; \rho_{2}=\frac{3}{16} \cdot \sum x_{1}^{2} S=64.76 \\
b_{0}=S_{13}=10.2 ; b_{1}\left(B_{1}\right)=\frac{1}{8} i B=\frac{1}{8} \cdot 2.7=+0.33 ; b_{2}\left(B_{2}\right)=\frac{1}{8} i B=\frac{1}{8} \cdot 21.8=+1.19 ; \\
b_{3}(H)=\frac{1}{8} i H=\frac{1}{8} \cdot 24.0=+3.0 ; \rho_{3}=\rho_{2}+\rho_{1}=64.76-71.8=-7.04 ; \\
b_{11}\left(x_{1}^{2}\right)=\frac{1}{4}(11 S)+\rho_{3}=\frac{1}{4} \cdot 8.41-7.04=13.99 ; b_{22}\left(x_{2}^{2}\right)=\frac{1}{4}(22 S)+\rho_{3}=\frac{1}{4} \cdot 103+\rho_{3}=18.71 ; \\
b_{33}\left(x_{3}^{2}\right)=\frac{1}{4}(15.83)-\rho_{3}=\frac{1}{4} \cdot 158.3-7.04=32.53 ; b_{12}=\frac{1}{4}(-3.8)=-0.95 ; b_{13}=\frac{1}{4} \cdot 25.6=+6.4 ; \\
b_{23}=\frac{1}{4}(-4.1)=-1.02
\end{gathered}
$$


According to the equation in general form:

$$
\begin{aligned}
& S=b_{0} \pm b_{1} x_{1} \pm b_{2} x_{2} \pm b_{3} x_{3} \pm b_{11}\left(x_{1}^{2}\right) \pm b_{22}\left(x_{2}^{2}\right) \pm b_{33}\left(x_{3}^{2}\right) \pm b_{11}\left(x_{1}^{2}\right) \pm b_{22}\left(x_{2}^{2}\right) \pm b_{33}\left(x_{3}^{2}\right) \pm \\
& \pm b_{12}\left(x_{1} x_{2}\right) \pm b_{13}\left(x_{1} x_{3}\right) \pm b_{23}\left(x_{2} x_{3}\right)
\end{aligned}
$$

Compiled dependence with actual values:

$$
\begin{aligned}
& S=10.2+0.33 B_{1}+1.19 B_{2}+3.0 H+13.99 B_{1}^{2}+18.71 B_{2}^{2}+32.53 H^{2}-0.95 B_{1} B_{2}+ \\
& +6.4 B_{1} H-1.02 B_{2} H
\end{aligned}
$$

According to the dependence 2, a ranged curve of the influencedegree of the mixer pressure factors $H$, vacuum in the suction pipe of the pump $B_{2}$ and vacuum in the mixer body $B_{l}$ (picture 10)is built.

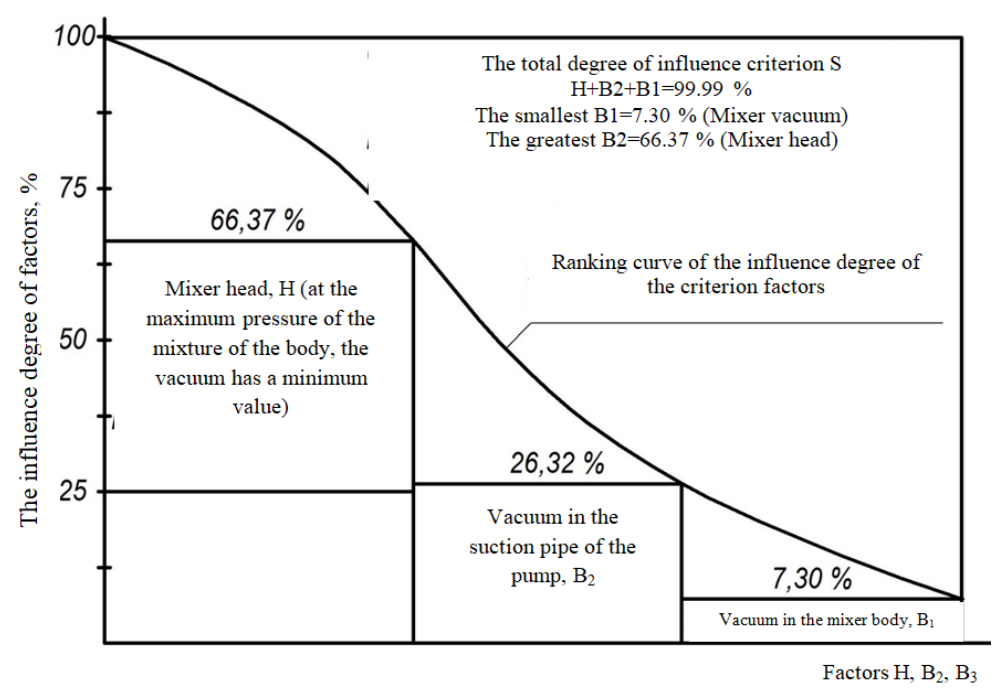

Fig. 10. The influence degree of the mixer pressure factors $H$, vacuum in the suction line of the centrifugal pump $B_{2}$ and vacuum in the mixer body $B_{1}$ on criterion $S$ - the amount of potential energy in the suction pipe of the mixer

Figure 10 shows that the maximum effect on the value of potential energy in the suction pipeline of the mixer $S$ exerts mixer pressure $H-66.37 \%$, minimum - vacuum in the mixer body $\mathrm{B}_{1}=7,30 \%$. In addition, to compare the experimental and calculated data for the dependence 2, the values of the criterion $S$ were calculated and are shown in Figure 11, from which it can be seen that the highest potential energy value of $15.6 \mathrm{~m}$ was obtained at the maximum vacuum values in the mixer body $(-8$ mand $18 \mathrm{~m})$ and medium vacuum in a centrifugal pump $(-3 \mathrm{~m})$. 


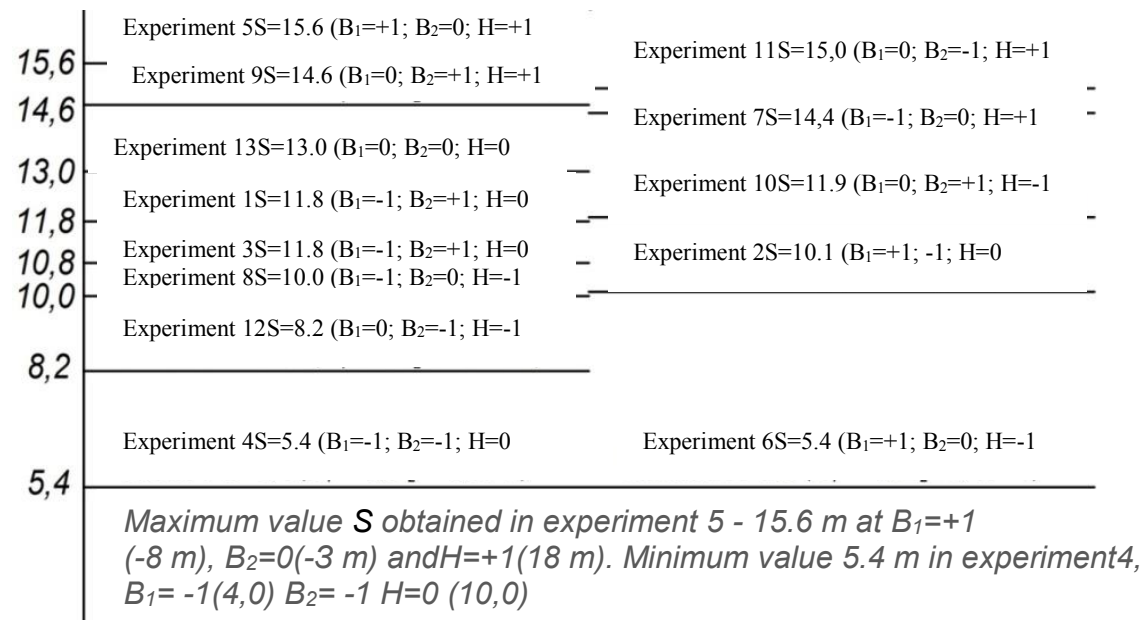

Factors $\mathrm{B}_{1}, \mathrm{~B}_{2}, \mathrm{H}$

Fig. 11. Values of potential $P$ energy in the suction pipeline of the mixer

Further research was carried out with two factors - the head of the mixer $H^{\prime}$ and vacuum in the suction pipe of the pump $B_{2}^{\prime}$ at a stable, taken according to the first group of experiments, the value of vacuum in the mixer housing $B_{1}=5 \mathrm{~m}$, with changed intervals of variation. The actual and coded values of the factors for the two-factor design are shown in Table 3. The planning matrix and the results of the second group of experiments are shown in Table 4.

Table 3. Actual and coded values of factors for the second group of experiments

\begin{tabular}{|c|c|c|c|c|c|}
\hline \multirow{2}{*}{ Factors } & Code & $\begin{array}{c}\text { Interval, } \\
\mathrm{m}\end{array}$ & \multicolumn{3}{|c|}{ Level } \\
\cline { 4 - 6 } & & Medium (0), m & Lower (-) & Upper (+) \\
\hline $\begin{array}{c}\text { Vacuum in the } \\
\text { suction pipe of } \\
\text { the pump, } B_{2}^{\prime}\end{array}$ & $x_{2}^{\prime}$ & 1.0 & $4.0(0)$ & $3.0(-)$ & $5.0(+)$ \\
\hline $\begin{array}{c}\text { Mixer head, } \\
H^{\prime}\end{array}$ & $x_{3}^{\prime}$ & 4.0 & $10.0(0)$ & $14.0(-)$ & $18.0(+)$ \\
\hline
\end{tabular}

Table 4. The planning matrix and the results of the second group of experiments

\begin{tabular}{|c|c|c|c|c|c|c|}
\hline \multirow{3}{*}{$\begin{array}{c}\text { Experi- } \\
\text { ment } \\
\text { no. }\end{array}$} & \multirow{3}{*}{$\begin{array}{l}\text { Vacuum in } \\
\text { the suction } \\
\text { pipe of the } \\
\text { pump } \\
x_{2}^{\prime}\left(B_{2}^{\prime}\right), \mathrm{m}\end{array}$} & \multirow{3}{*}{$\begin{array}{c}\text { Mixer } \\
\text { head } \\
x_{3}^{I}\left(H_{1}^{I}\right), \mathrm{m}\end{array}$} & \multicolumn{2}{|c|}{ Factor values, $\mathrm{m}$} & \multirow{3}{*}{$x_{2}^{\prime} \cdot H$} & \multirow{3}{*}{$\begin{array}{l}\text { Criterion (total } \\
\text { energy in the } \\
\text { suction pipe of } \\
\text { the mixer), } \\
\quad S_{2}, \mathrm{~m}\end{array}$} \\
\hline & & & $B_{2}^{\prime}$ & $H^{\prime}$ & & \\
\hline & & & $x_{2}$ & $x_{3}$ & & \\
\hline 1 & + & + & 5.0 & 18.0 & +21.4 & 21.4 \\
\hline 2 & + & - & 5.0 & 10.0 & -20.4 & 20.4 \\
\hline 3 & - & + & 3.0 & 18.0 & -15.0 & 15.0 \\
\hline 4 & - & - & 3.0 & 10.0 & +13.0 & 13.0 \\
\hline 5 & + & 0 & 5.0 & 14.0 & 0 & 10.1 \\
\hline
\end{tabular}




\begin{tabular}{|c|c|c|c|c|c|c|}
\hline 6 & - & 0 & 3.0 & 14.0 & 0 & 16.2 \\
\hline 7 & 0 & + & 4.0 & 18.0 & 0 & 17.0 \\
\hline 8 & 0 & - & 4.0 & 10.0 & 0 & 13.4 \\
\hline 9 & 0 & 0 & 4.0 & 14.0 & 0 & 12.3 \\
\hline \multicolumn{7}{|c|}{$\begin{array}{l}\text { Processing of the results (determination of the intercept value and the coefficients of } \\
\text { the factors) }\end{array}$} \\
\hline & \multirow{4}{*}{$\begin{array}{l}\sum(+)=51.9 \\
\sum(-)=44.4 \\
10 \Pi_{2}^{\prime}=+7.5\end{array}$} & \multirow{4}{*}{$\begin{array}{l}\sum(+)=53.4 \\
\sum(-)=47.0 \\
20 \Pi_{2}^{\prime}=+6.4\end{array}$} & $11 O S_{2}$ & $22 \mathrm{OS}_{2}$ & \multirow{4}{*}{$\begin{array}{l}\sum(+)=34.4 \\
\sum(-)=-35.4 \\
12 O S_{2}=-1\end{array}$} & \multirow[t]{4}{*}{$O S_{2}=139.0$} \\
\hline & & & -063 & -1004 & & \\
\hline & & & & & & \\
\hline & & & \multicolumn{2}{|c|}{$\begin{array}{l}11 \mathrm{OS}_{2}+22 \mathrm{OS}_{2}= \\
=196.7\end{array}$} & & \\
\hline
\end{tabular}

\begin{tabular}{|c|c|c|c|}
\hline \multicolumn{3}{|c|}{$\begin{array}{l}\sum 11 O S_{2}=196.7 \\
\rho_{3}=-\frac{1}{3} \sum 11 O S_{2}-1 / 3196.7= \\
=-65.56\end{array}$} & \multirow{3}{*}{$\begin{array}{l}\rho_{1}=-\frac{1}{3} O S_{2}=139 / 3 \\
=-46.33 \\
\rho_{2}=\frac{5}{9} O S_{2}^{\prime} \\
=77.22 \\
b_{0}=\rho_{2}+\rho_{3}= \\
77.22-65.5= \\
=11.72\end{array}$} \\
\hline \multicolumn{2}{|c|}{$\frac{1}{2} 11 O S_{2} 1 / 222 O S_{2}$} & \multirow{3}{*}{$\begin{array}{l}b_{12}=\frac{1}{4}= \\
=\frac{1}{4} 12 O S_{2} \\
=-\frac{1}{4}\end{array}$} & \\
\hline 48.15 & 50.2 & & \\
\hline \multirow{2}{*}{\multicolumn{2}{|c|}{$\begin{array}{l}b_{i i}=\frac{1}{2} i i+\rho_{1}^{\prime} \\
b_{11}=48.15-46.33 \\
=1.82 \\
b_{22}=-\frac{1}{4}\end{array}$}} & & \\
\hline & & \multicolumn{2}{|c|}{$\begin{array}{l}b_{1}=1 / 6 \cdot 10 S_{2}^{\prime}=1 / 6 \cdot 7, .5=1.25 \\
b_{2}=1 / 6 \cdot 20 S_{2}^{\prime}=1 / 6 \cdot 6.4=1.06\end{array}$} \\
\hline
\end{tabular}

According to the equation in general form

$$
S_{2}=b_{0}^{\prime} \pm b_{1} x_{2}^{\prime} \pm b_{2} H^{\prime} \pm b_{11} x_{2}^{\prime 2} \pm b_{11} H^{\prime 2} \pm b_{12} x_{2}^{\prime} H^{\prime}
$$

the dependence is written in natural values (4), according to which the maximum and minimum values of the criterion (total energy) $S_{2}$ in the suction pipe of the mixer (table 5).

$$
S_{2}=11.72+1.25 x_{2}^{\prime}+1.06 H_{1}^{\prime}+1.82 x_{2}^{\prime 2}+3.87 H_{1}^{\prime 2}-\frac{1}{4} x_{2}^{\prime} H_{1}^{\prime}
$$


The analysis of the second group experiments'results on the calculated values of the potential energy values according to the dependence 4 is shown in Table 5 and in Figure 11.

The calculated values of the criterion $S$ in the mixer suction pipe are calculated according to the dependence 4 .

Table 5. Calculated values of the criterion $S$ in the suction pipe of the mixer

\begin{tabular}{|c|c|c|c|c|c|}
\hline \multirow{2}{*}{$\begin{array}{c}\text { Experiment } \\
\text { no. }\end{array}$} & \multicolumn{2}{|c|}{$\begin{array}{c}\text { Centrifugal pump vacuum } \\
\mathrm{B}_{2}\end{array}$} & \multicolumn{2}{c|}{ Mixer head $\mathrm{H}_{1}$} & \multirow{2}{*}{$\begin{array}{c}\text { Criterion, } \mathrm{S}_{2}, \\
\mathrm{~m}\end{array}$} \\
\cline { 2 - 5 } & code & dimension & code & dimension & \\
\cline { 2 - 5 } & $x_{2}^{\prime}$ & $B_{2}, \mathrm{~m}$ & $x_{3}^{\prime}$ & $H_{1}, \mathrm{~m}$ & \\
\hline 1 & + & 5.0 & + & 18.0 & 19.47 \\
\hline 2 & + & 5.0 & - & 10.0 & 17.35 \\
\hline 3 & - & 3.0 & + & 18.0 & 16.97 \\
\hline 4 & - & 3.0 & - & 10.0 & 14.85 \\
\hline 5 & + & 5.0 & 0 & 14.0 & 14.79 \\
\hline 6 & - & 3.0 & 0 & 14.0 & 12.29 \\
\hline 7 & 0 & 4.0 & + & 18.0 & 16.65 \\
\hline 8 & 0 & 4.0 & - & 10.0 & 14.53 \\
\hline 9 & 0 & 0 & 4.0 & 14.0 & 11.72 \\
\hline
\end{tabular}

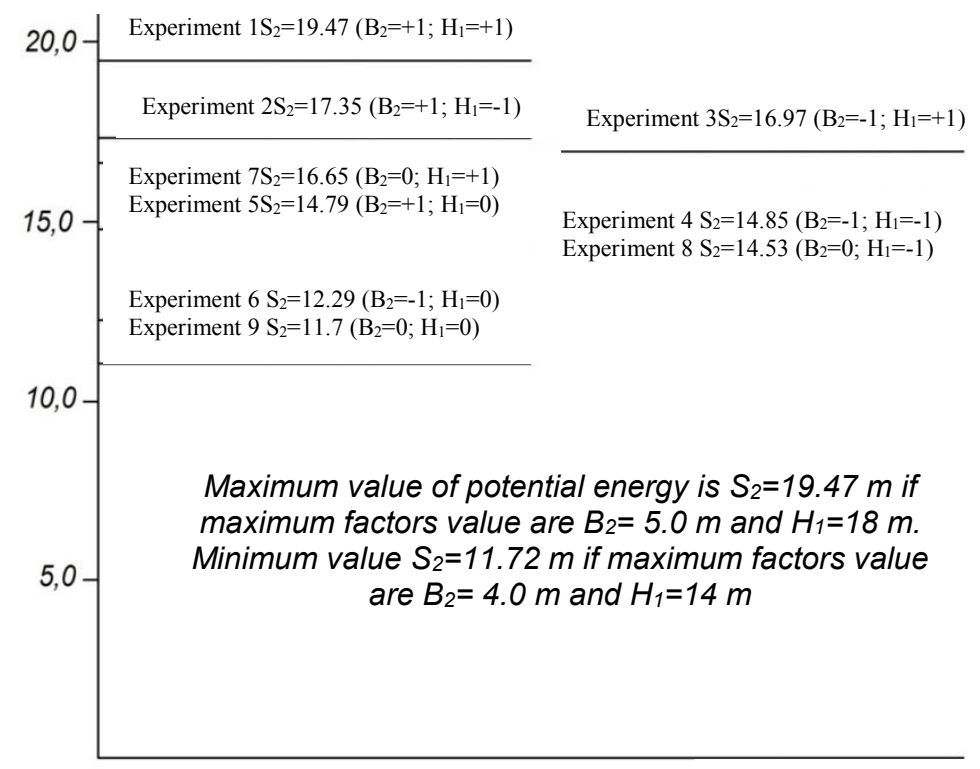

Factors $B_{2}, H_{1}$

Fig. 12. Potential energy values $S$ in the mixer suction pipeline according to the results of the second group of experiments with a stable vacuum value in the mixer body $B_{1}=-5 \mathrm{~m}$.

An analysis of the data obtained from the results of the studies carried out showed that the maximum value of energy in the mixer suction pipeline, both according to the 
experimental data (Tables 2.4) and calculated according to the obtained equations $(2,4)$, fluctuates within 10-20 m, which makes it possible to calculate the hydraulic parameters of the fertilizer supply system to the suction pipelines of pumping stations, regardless of the hydromechanical equipmentcharacteristics.

\section{Conclusion}

As a result of the experimental studies, mathematical dependences were obtained for the development of the foundations for calculating the possibility of determining the place of the fertilizer mixer installation on the pumping station territory.

\section{References}

1. E.A. Chaika, V.A. Timoshenko, Machinery and equipment for environmental management and environmental protection: collection of scientific works, Novocherkassk state reclamation academy, Novocherkassk 6, 84-90 (2010).

2. A.S. Tarasyants, D.V. Urzhumov, Yu.S. Urzhumova, Bulletin of the higher educational institutionsNorth Caucasus. Technical sciences 10, 103-105 (2006).

3. V.A. Rudakov, K.A. Degtyareva, Yu.S. Urzhumova, S.A. Tarasyants, Patent No. 193355. Russian Federation, MPKA01 C23/04, Four-component jet pump mixer, Applicant and patentee "Don State Agrarian University" - No. 2019111839; appl.18.04.19; publ. 25.10.2019, Bul. No. 12 .

4. V.A. Voznesensky, Statistical methods for planning an experiment in technical and economic research (Statistics, Moscow, 1974).

5. E.A. Chayka, Technologies and means of mechanization inAIC: collection of scientific works, Novocherkassk state reclamation academy, Novocherkassk, 2009.

6. V.E. Fridman, Hydroelevators (Mashgiz, Moscow, 1990).

7. V.E. Lyamaev, Hydro-jet pumps and installations (Mechanical engineering, Leningrad, branch, 1988).

8. V.G. Tsegelsky, Inkjet devices (Publishing house of MSTU named affter N. E. Bauman, Moscow, 2017).

9. N.A. Rzhanitsyn, Water-jet pumps (Publishing house of energetic literature, Moscow, 1988).

10. N.A. Rzhanitsyn, Water-jet pumps (Energoizdat, Moscow, 1980). 